\title{
IMPORTANCIA DO CONJUGADO ARTERIA CAROTIDA INTERNA-SEIO CAVERNOSO
}

\author{
MILTON BAGGIO MOREIRA*
}

Não acreditamos que a artéria carótida interna esteja dentro do seio cavernoso por um simples capricho da natureza ou por economia de espaço dentro do crânio. Também não acreditamos que o sifão carotídeo somente constitua um percurso bizarro da artéria, sem significado e importância. Por julgar estes aspectos morfológicos necessários, resolvemos estudá-los apresentando, inicialmente, nossa interpretação e conceito a respeito e, em seguida, empreendendo o estudo e a pesquisa correspondente para a demonstração, o que será feito em outro trabalho.

\section{DETALHES ANATOMICOS}

A artéria carótida interna penetra no crânio através do canal carotídeo que se encontra na porção petrosa do osso temporal. Neste trajeto, ela é envolvida pelo plexo venoso carotideo que se apresenta em forma de rede que a circunda e pelo plexo nervoso carotídeo interno 6. Quando a artéria emerge dentro do endocrânio, no vértice do rochedo, através do orifício interno do canal carotídeo, localiza-se dentro do seio cavernoso da dura-mater 6, pelo qual circula sangue venoso de retorno encefálico.

Ainda dentro do canal carotídeo a artéria sofre sua primeira curvatura. Ao sair palo orifício interno deste canal, ela descreve a sua segunda curvatura, completada no interior do seio cavernoso onde também realiza a sua terceira curvatura. A quarta curvatura ela efetua ao sair do seio cavernoso, no espaço sub-aracnóideo. $O$ túnel osseo, representado pelo canal carotídeo, suporta e protege a parede vascular e o plexo venoso que a circunda.

O seio cavernoso, como o seu nome indica, apresenta constituição cavernosa, trabeculizado em torno da artéria. Sabemos que os demais lugares no organismo onde existem plexos venosos cavernosos, como a glande, corpos cavernosos do pênis e uretra possuem capacidade de maior retenção de sangue venoso e que devido à maior tensão consequente podem se tornar túrgidos e rijos quando necessário. Existem dois grupos de seios venosos da dura-mater: o primeiro, representado pelios seios sagital superior, sagital inferior, reto, laterais e occipitais posteriores; o segundo grupo inclue os seios cavernosos, coronários, esfeno-parietais, petrosos superiores e inferiores, occipital transversal ou basilar, carotídeos, petro-occipitais e veias oftálmicas (tributárias)6.

O seio cavernoso é o centro do segundo grupo. Os demais são seus afluentes ou emissários. Poderiamos dizer que lhe servem como aferentes ou eferentes, podendo inverter-se o sentido da circulação nestes conforme a necessidade do momento 6. Podemos considerar como aferentes o seio coronário, as veias oftálmicas, os seios esfenoparietais e as veias do seio esfenoidal. Como eferentes ao seio cavernoso, consideramos: os seios petrosos superior e inferior, o seio occipital transversal ou basilar, os seios

- Professor Adjunto de Neuro-Anatomia da Universidade Federal do Paraná; Professor de Neurologia na Faculdade Evangélica de Medicina do Paraná. 
carotideos e petro-occipitais inferióres. Ainda temos as veias emissárias do seio carvernoso que săo as oftálmicas que funcionarăo como eferentes, drenando para a veia facial quando aumenta a tensăo dentro do seio cavernoso, invertendo o sentido habitual da corrente sanguínea 6 e também as velas dos forames oval, redondo e lacero, as veias meníngeas entre as quais as meníngeas médias formando a encruzilhada venosa de Trolard, dentro da qual transita a artéria meníngea média semelhante ao conjugado carotídeo-cavernoso. O ramo anterior da vela meníngea média também pode terminar dentro do seio cavernoso 6.

Os selos cavernosos comunicam-se amplamente entre si, direta ou indiretamente, principalmente através dos seios coronários e basilar ou occipital transversal 6.

Embora os dois grupos de selos venosos. da dura-mater comuniquem-se entre si, parece que podem funcionar com caracteristicas proprias, dentro de certos limites, e como dois sistemas. O sangue flui do que se encontra com maior tensăo em relaçăo ao outro através das vias anastomóticas ou de comunicaçăo entre os mesmos 6.

As drenagens do grupo anterior poderăo se realizar por meio das múltiplas vias de escoamento do grupo posterior, como também diretamente para os plexos pterigói leos, faringeos, e pelas veias faciais.

\section{CONCEPÇAO FISIOLOGICA}

Não obstante as múltiplas vias de drenagem do seio cavernoso, admitimos que ele constitui um caso especial no sistema venoso intracraniano, exatamente por sua constituição morfológica diferente de todos os demais seios venosos e veias, devendo se correlacionar com fisiologia própria e peculiar.

As suas aferências e eferências deverão lhe servir de forma útil no desempenho de suas funções. Acreditamos que não é por acaso que a artéria carótida interna transita em seu interior, mas para poder satisfazer uma recessidade imperiosa relacionada com a circulação encefálica. Da mesma forma também consideramos que o plexo venoso que envolve a carótida interna dentro do canal carotídeo e que é a continuação do seio cavernoso, tem importância e significado fisiologico, não sendo apenas um detalhe anatômico ou uma curiosidade.

A superfície interna da artéria carótida dentro do seio cavernoso é menor que a superfície interna da soma dos seus ramos colaterais e terminais. A quantidade de sangue que circula no seu interior na unidade de tempo é maior que em qualquer segmento dos seus ramos. Portanto, cada ponto de sua parede está sujeito a pressão maior que cada ponto da parede de seus ramos. Uma elevação súbita da pressão arterial sujeitaria com maior facilidade a ruptura de sua parede que a dos seus ramos, caso ela não transitasse por dentro desta câmara líquida sanguínea chamada seio cavernoso, onde existe uma tensão venosa por fora da parede arterial que a escora e protege, especialmente nos casos de hipotensão liquórica por escoamento de líquido cefalorraqueano como, por exemplo, em casos de traumatismos cranianos. Não obstante a pressão venosa intracraniana nos demais seios durais e veias quase não se modifique, a não ser em casos especiais $1,3,4$, devido às amplas drenagens - para os plexos venosos vertebrais, veia jugular interna, veias emissárias, plexo faríngeo, pterigóideo e outras veias exo-cranianas - acreditamos que o seio cavernoso possui pressão venosa especial própria e variável em decorrência de sua constituição anatômica. Dentro de determinados limites e necessidades pode regular o fluxo sanguíneo através da carótida interna, não the permitindo distender-se livremente nas crises hipertensivas arteriais. $O$ plexo venoso carotídeo dentro do canal carotídeo 
completa esta ação, como também a protege, além do próprio canal ósseo inextensível que serie para o mesmo fim.

Não excluimos a importância que o plexo nervoso carotídeo interno exerce sobre as paredes vasculares, também desempenhando controle e regulaçã̀o do fluxo sanguíneo, bem como o mecanismo do seio carotídeo muito conhecido 1,4 . Embora nas hipertensões arteriais a pressão venosa dos demais seios durais e veias possa não se alterar de forma significativa, não consideramos o mesmo para a tensão venosa dentro do seio cavernoso. Acreditamos que aqui haja participação no mecanismo da resistência cérebro-vascular através de modificações da tensão venosa intra-cavernosa (devido à sua constituição morfológica), servindo para controle e regulação do fluxo sanguíneo cerebral.

Sabemos que a parede da artéria carótida interna ć predominantemente elástica em relação à sua constituição muscular, o que a sujeita mais diretamente às variações físicas das tensões sanguíneas relacionadas à hemodinâmica. $O$ aspecto morfológico cavernoso do seio dural e suas anastomoses lhe permitindo maior ou menor contenção sanguínea e consequente variação da sua tensão venosa na dependência das necessidades ocasionais, acarretam maior ou menor pressão externa sobre a parede da artéria carótida interna. Desta forma possibilita contensão ou dỉstensão da artéria, permitindo-lhe ou não maior calibre. Disto poderá resultar o controle do fluxo sanguíneo carotídeo, nas variações da pressão arterial, porquanto a quantidade de sangue e oxigênio que deve chegar ao cérebro deve se manter quase conștante, não obstante as variações da pressão arterial.

Também julgamos que nas hipotensões arteriais graves que determinam a vertigem e queda do paciente a ação do seio cavernoso é importante para facilitar a chegada do sangue ao encéfalo sem precisar vencer a força da gravidade (por escoamento do sangue venoso através das suas vias de drenagem); o sifão carotideo passa a funcionar então dentro do princípio que rege o funcionamento do sifão em hidrodinâmica, facilitando o escoamento líquido e a chegada do sangue ao cérebro para evitar a anoxia resultante e descerebração consequente.

\section{RESUMO}

O autor considera necessário o conjugado anatômico artério-venoso representado pela artéria carótida interna e seio cavernoso, bem como o plexo venoso carotide que reveste a carótida interna dentro do caral carotídeo da porção petrosa do osso temporal. Julga que, além de proteger a parede vascular arterial nas hipertensões arteriais súbitas, possa contribuir no mecanismo de controle $\mathrm{e}$ regulação do fluxo sanguíneo carotídeo, por considerar diferentes as condições fisiológicas do seio cavernoso em relação aos demais seios venosos durais e o sistema venoso endocraniano; consequente de sua constituição cavernosa, diferente dos demais canais sanguíneos venosos, com fisiollogia venosa própria e funções diferentes. Procura assemelhá-los aos demais distritos do organismo em que existem plexos cavernosos nos quais a tensão venosa chega a grandes proporções, comparada às ćemais regiões em que não existe esta constituição morfológica. Estabelece a correlação resultante ao mecanismo de resistência cérebro-vascular do qual considera participar, diferindo dos demais seios durais 
e veias encefálicas. Ainda valoriza o sifão carotídeo fisiologicamente e julga que o mesmo participa da hemodinâmica quando o paciente se encontra caído (em plano horizontal) com hipotensão arterial, favorecendo a chegada sanguínea ao cérebro, evitando a anóxia e descerebração consequente dentro de determinados limites, sendo mais um meio de defesa do organismo.

\section{SUMMARY}

\section{Physiological importance of the internal carotid artery-cavernous sinus conjugate}

The author considers of atmost importance the anatomical arterial-venous conjugate, represented by the internal carotid artery and the cavernous sinus, as well as the carotid venous plexus which covers the internal carotid artery within the petrous portion of the temporal bone. He believes that besides protecting the vascular arterial wall in acute episodes of hypertension, it can also contribute to the mechanism of the carotid blood flow. This is due to the fact that he considers the physiological conditions of the cavernous sinus in relation to the others dural venous sinuses and the endocranial venous system and its cavernous constitution, which differs from other venous blood canals with their own venous physiology and different functions. He attempts to compare it to the rest of the body areas where cavernous plexuses are localized and where venous pressure reachs high proportions, in comparison with the other regions without this morphologic constitution. He establishes a correlation resulting form the cerebro-vascular resistence mechanism, the participation of which he considers as differing from others dural sinuses and encephalic veins. He also emphasizes physiologically the carotid siphon and believes that it participates in the hemodynamics, when the patient is lying down (in a horizontal position) with hypotension, facilitating the blood access to the brain, thus avoiding consequent anoxia and decerebration, within certain limits, and constituting an additional mean of body defense.

\section{REFERFNCIAS}

1. CROSBY, E. C.; HUMPREY, T. \& LAUER, E. W. - Correlative Anatomy of the Nervous System. The MacMillan Co., New York, 1962, págs. 665/571.

2. MARSHALL, J. - Diagnostico y Tratariento de las Afecciones Cerebro-Vasculares. Versåo castelhana. Erditorial Jims, Barcelona, 1970. págs. 1/20.

3. MELARAgNO FILHO, R. - Acidentes Vasculares Cerebrais. In CANBLAS H. M., editor - Manual de Clínica Neurológica. Sarvier Ed., Såo Paulo, 1967, pág. 63/74.

4. MELARAGNO FILHO, R. \& SANVITO, W. L. - Doenças Vasculares do Encéfalo. Liv. Manole I.C. Ltda., Såo Paulo, 1975, págs. 3/14.

5. PERNKOPF, E. - Anatomia Topografica Humana. Tomo 4 (primeira parte). Ed. Labor S/A., Barcelona, 1968, figs. 66 e 66 a, 66 b e 73 b.

6. TESTUT, L. \& LATARJET, A. - Tratado de Anatomia Humana. Tomo 2. Verăo castelhana. Salvat Ed., Barcelona, 1954 págs. 251/254 e 446/467.

7. TRUEX, R.; CARPENTER, M. B. \& MOSOVICH, A. - Neuroanatomia Humana, 4. ediçro. Versåo castelhana. El Tteneo E., Buenos Aires, 1973, págs. 78/86.

Rua Coronel Dulcidio 1383 - 80000 Curitiba, PR - Brasil. 